\title{
Электрохимическая миграция. Борьба с невидимым врагом
}

\author{
Р. Порядин ${ }^{1}$
}

УДК 621.3:544.6 | ВАК 05.27.01

\begin{abstract}
Электрохимическая миграция (ЭХМ) - один из важных процессов, влияющих на надежность и долговечность электронных блоков, и она то и дело попадает в список возможных причин эксплуатационных отказов. Все чаще возникают вопросы о причинах дефектов и сбоев, вызванных загрязнениями различной природы в совокупности с высокой влажностью. И электрохимическая миграция здесь является одной из ключевых причин. Например, автомобильная, специальная и телекоммуникационная отрасли обязаны гарантировать работоспособность электронных узлов в любой климатической зоне в условиях сильных колебаний температур и экстремальной влажности. Поэтому необходимо понимать, какие процессы протекают в изделиях в жестких климатических условиях при наличии различных загрязнений на поверхности.

В статье мы рассмотрим механизм, причины возникновения и методы предотвращения электрохимической миграции, а также ее отличия от других типов отказов в электронных изделиях.
\end{abstract}

лектрохимическая миграция (электрохимическая коррозия) - это тип коррозии, которая протекает под действием приложенного электрического напряжения при обязательном присутствии электролита и металлов с различающимися окислительно-восстановительными потенциалами (электродными потенциалами).

Электрохимическая миграция - наиболее распространенный тип коррозии. По электрохимическому механизму корродируют металлы, находящиеся в контакте с растворами электролитов (морская вода, остатки флюсов, солей, щелочей). Для радиоэлектроники примером может служить ситуация, когда на печатном узле остатки флюса оказываются между двумя проводниками в условиях конденсации влаги; возникает ток утечки, который приводит к возникновению электрохимической миграции и росту дендритов. Этот процесс уменьшает надежность и срок службы электронных изделий и часто является причиной отказов, связанных с работой в агрессивных условиях

ООО «Остек-Интегра», главный специалист отдела технического сопровождения,

Poryadin.R@ostec-group.ru. окружающей среды. Типовые признаки электрохимической миграции - временные и постоянные короткие замыкания. Даже временные короткие замыкания могут приводить к отказу электронных устройств, вызывая сбои в их работе. Постоянные короткие замыкания могут вызывать локальный перегрев печатного узла, приводящий к выгоранию компонентов или участка печатной платы.

Чтобы определить наличие электрохимической миграции, необходимо исследовать поврежденные платы в лабораторных условиях под сканирующим электронным микроскопом, а это часто не представляется возможным. Поэтому подобные отказы причисляются
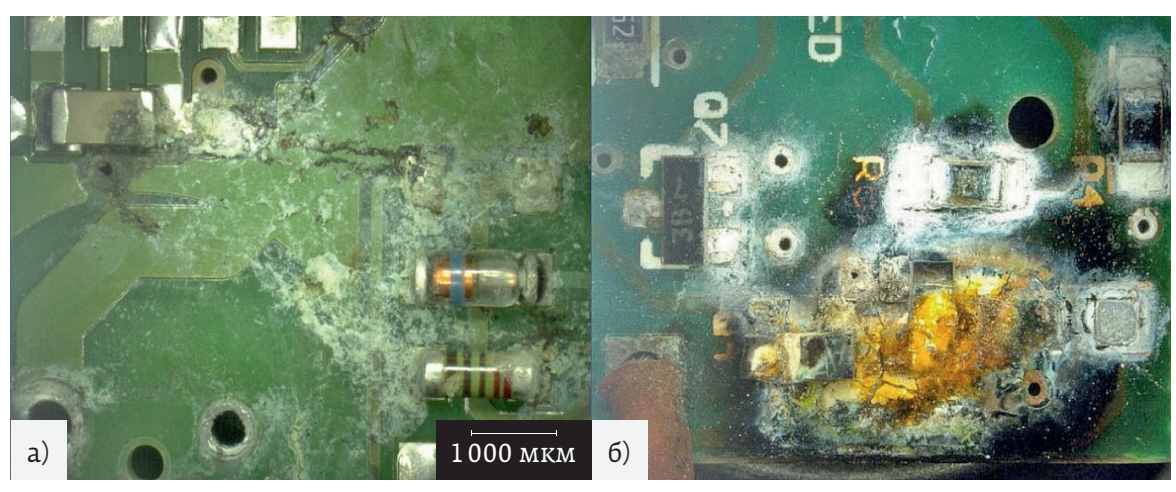

Рис. 1. Повреждения, вызванные электрохимической миграцией (а) и пробоем диэлектрика (б) 
к функциональным сбоям, пробоям диэлектрика или воздействию токов утечки (рис. 1).

Чаще всего очень сложно или невозможно установить, что причиной отказа стала именно электрохимическая миграция. В течение непродолжительного времени конденсации влаги (обычно несколько минут) образуются непроводящие дендриты малого размера, которые быстро выгорают, но приводят к выходу изделия из строя.

Каким образом возникает электрохимическая миграция? Как оценить риски и, самое важное, их избежать? Чтобы ответить на эти вопросы, необходимо детально исследовать лежащие в ее основе процессы.

\section{МЕХАНИЗМ ВОЗНИКНОВЕНИЯ ЭЛЕКТРОХИМИЧЕСКОЙ МИГРАЦИИ}

Электрохимическая миграция может протекать в любом участке печатного узла при наличии высокого электри ческого напряжения и загрязнений, оставшихся после
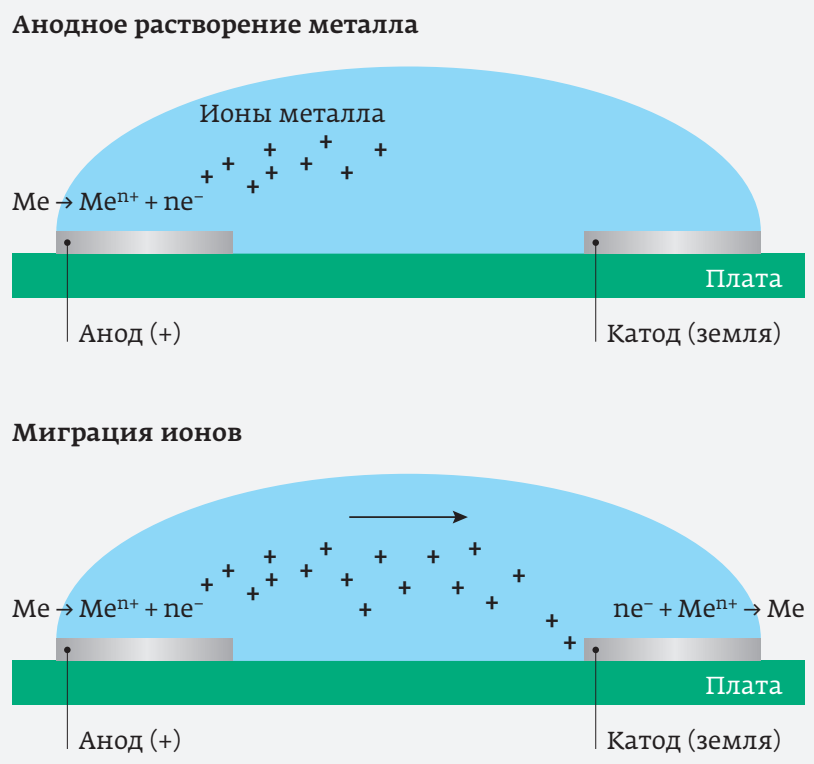

Осаждение ионов (катодный процесс)

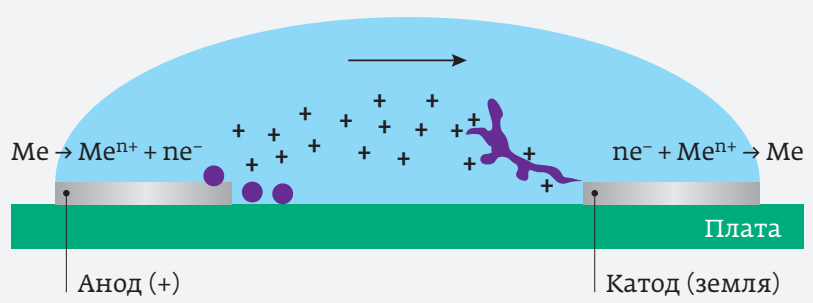

Рис. 2. Схематическое представление механизма возникновения электрохимической миграции

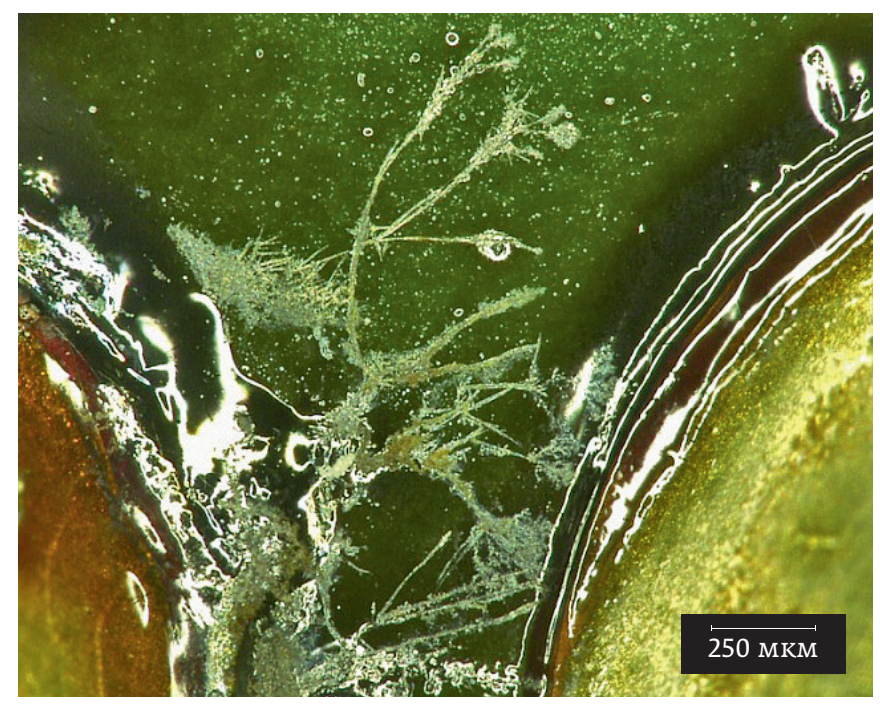

Рис. 3. Образование металлических структур

процесса пайки, некачественной отмывки или при неправильном манипулировании печатным узлом.

Стандартный алгоритм возникновения электрохимической миграции выглядит следующим образом (рис. 2):

- анодное растворение металла (Me $\rightarrow \mathrm{Me}^{\mathrm{n+}}+\mathrm{ne}^{-}$)

- миграция ионов металлов;

- катодное осаждение ионов металлов $\left(n e^{-}+\mathrm{Me}^{\mathrm{n}+} \rightarrow \mathrm{Me}\right)$.

Под воздействием электрического напряжения проводник-анод растворяется, отдавая в электролит положительно заряженные ионы металла. Эти ионы направляются к проводнику-катоду и восстанавливаются на нем до металлического состояния, образуя проводящие перемычки в виде дендритоподобной рыхлой металлической структуры (рис. 3). Если концентрация ионов в электролите велика, образуются более гладкие структуры в виде пучков волокон или полос (рис. 4). В результате этих процессов за несколько минут могут
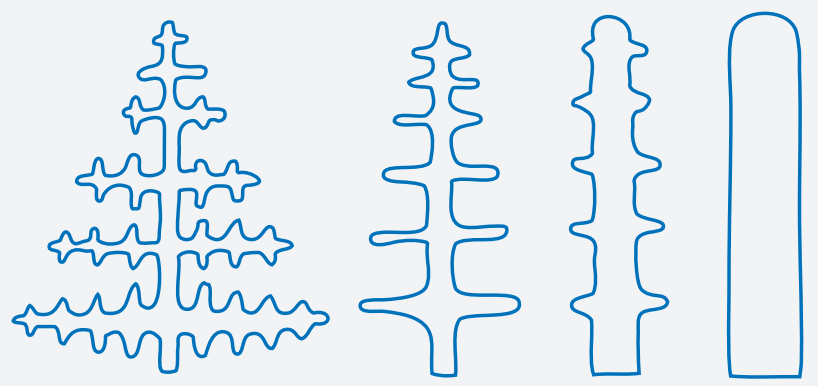

Рис. 4. Виды структур роста: пучки волокон и полосы 
Таблица 1. Стандартные электродные потенциалы металлов

\begin{tabular}{ll|ll} 
Электрод & $\mathrm{E}^{0}, \mathrm{~B}$ & Электрод & $\mathrm{E}^{0}, \mathrm{~B}$ \\
$\mathrm{Li}^{+} / \mathrm{Li}$ & $-3,05$ & $\mathrm{Cd}^{2+} / \mathrm{Cd}$ & $-0,40$ \\
\hline $\mathrm{Rb}^{+} / \mathrm{Rb}$ & $-2,93$ & $\mathrm{Co}^{2+} / \mathrm{Co}$ & $-0,28$ \\
\hline $\mathrm{K}^{+} / \mathrm{K}$ & $-2,92$ & $\mathrm{Ni}^{2+} / \mathrm{Ni}$ & $-0,25$ \\
\hline $\mathrm{Cs}^{+} / \mathrm{Cs}$ & $-2,92$ & $\mathrm{Sn}^{2+} / \mathrm{Sn}$ & $-0,14$ \\
\hline $\mathrm{Ba}^{2+} / \mathrm{Ba}$ & $-2,90$ & $\mathrm{~Pb}^{2+} / \mathrm{Pb}$ & $-0,13$ \\
\hline $\mathrm{Ca}^{2+} / \mathrm{Ca}$ & $-2,87$ & $\mathrm{Fe}^{3+} / \mathrm{Fe}$ & $-0,04$ \\
\hline $\mathrm{Na}^{+} / \mathrm{Na}$ & $-2,71$ & $2 \mathrm{H}^{+} / \mathrm{H}$ & $-0,00$ \\
\hline $\mathrm{Mg}^{2+} / \mathrm{Mg}$ & $-2,37$ & $\mathrm{Sb}^{3+} / \mathrm{Sb}$ & $+0,20$ \\
\hline $\mathrm{Al}^{3+} / \mathrm{Al}$ & $-1,70$ & $\mathrm{Bi}^{3+} / \mathrm{Bi}$ & $+0,22$ \\
\hline $\mathrm{Ti}^{2+} / \mathrm{Ti}$ & $-1,60$ & $\mathrm{Cu}^{2+} / \mathrm{Cu}$ & $+0,34$ \\
\hline $\mathrm{Zr}^{4+} / \mathrm{Zr}$ & $-1,58$ & $\mathrm{Cu}^{+} / \mathrm{Cu}$ & $+0,52$ \\
\hline $\mathrm{Mn}^{2+} / \mathrm{Mn}$ & $-1,18$ & $\mathrm{Hg}_{2}^{2+} / 2 \mathrm{Hg}$ & $+0,79$ \\
\hline $\mathrm{V}^{2+} / \mathrm{V}$ & $-1,18$ & $\mathrm{Ag}^{+} / \mathrm{Ag}$ & $+0,80$ \\
\hline $\mathrm{Cr}^{2+} / \mathrm{Cr}$ & $-0,91$ & $\mathrm{Hg}^{2+} / \mathrm{Hg}$ & $+0,85$ \\
\hline $\mathrm{Zn}^{2+} / \mathrm{Zn}$ & $-0,76$ & $\mathrm{Pt}^{2+} / \mathrm{Pt}$ & $+1,19$ \\
\hline $\mathrm{Cr}^{3+} / \mathrm{Cr}$ & $-0,74$ & $\mathrm{Au}^{3+} / \mathrm{Au}$ & $+1,50$ \\
\hline $\mathrm{Fe}^{2+} / \mathrm{Fe}$ & $-0,44$ & $\mathrm{Au}^{+} / \mathrm{Au}$ & \\
\hline & & & +10 \\
\hline
\end{tabular}

создаваться нитевидные кристаллы толщиной в несколько микрон и длиной до десятков миллиметров.

скорость электрохимической миграции зависит от температуры, влажности и загрязнений на печатном узле, а также от соотношения электродных потенциалов металлов и сплавов паяных соединений и материалов компонентов. Причем электродный потенциал анода должен быть меньше электродного потенциала катода, только при этом условии возможна миграция (табл. 1)

Вещества, повышающие скорость коррозии, называют стимуляторами; вещества, которые снижают скорость коррозии - ингибиторами. Например, кислород является одновременно и стимулятором, и ингибитором. Он способствует улучшению защитно-окисной пленки, то есть действует как ингибитор, уменьшает вероятность коррозии, сокращает число очагов, в которых может возникнуть коррозийный процесс. Вместе с тем кислород повышает скорость коррозии в начавших корродировать точках, действует стимулирующе, поскольку является сильным катодным деполяризатором [1].

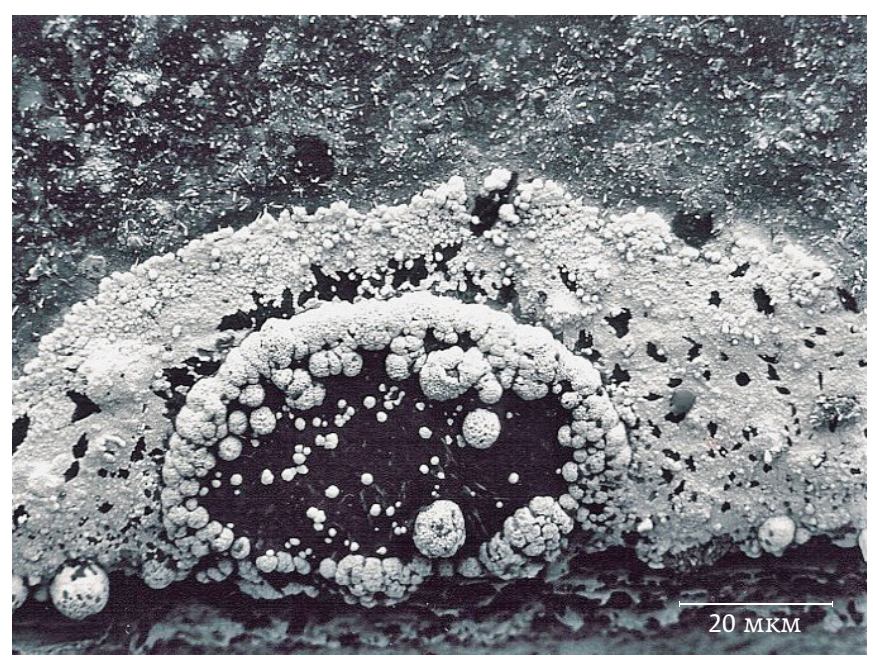

Рис. 5. Коррозия, вызванная коррозионными газами

\section{ПРЕДПОСЫЛКИ ВОЗНИКНОВЕНИЯ ЭЛЕКТРОХИМИЧЕСКОЙ МИГРАЦИИ}

Причины возникновения электрохимической миграции могут быть различными. Обычно процесс протекает под влиянием нескольких причин, одна из которых является доминирующей. Электрохимическая миграция возникает:

1. При наличии неоднородностей на поверхности паяного соединения или металлизации выводов и различных физических условий (включение примесей других металлов; наличие неодинаковых внутренних напряжений в различных точках металла или сплава).

Металлы и сплавы неоднородны. При соприкосновении их с электролитами (кислотами, щелочами, солями) одни участки поверхности металла играют роль анода (отдают электроны), а другие (различного рода включения) - катода (принимают электроны). На поверхности металла возникает множество микрогальванических пар, при этом чем больше неоднородность металла, тем больше скорость роста металлических дендритов.

2. При присутствии загрязнений и влаги на поверхности печатного узла (остатки флюса и отмывочной жидкости, коррозионные газы и др.). Влага может образоваться на печатном узле двумя способами: во-первых, вследствие адсорбции и, во-вторых, при конденсации.

Адсорбированное количество влаги зависит главным образом от поверхностной энергии, полярности и пористости материалов, в частности, используемых в паяльных масках. Для возникновения коррозии достаточно адсорбированной пленки толщиной всего несколько молекулярныхслоев. 
Наряду с адсорбцией к электрохимической миграции может приводить конденсация, вызванная перепадами температуры. В отличие от адсорбированной влаги конденсат концентрируется в теплоинерционных областях (слоях металлизации) или в местах загрязнений [2]. Типовые загрязнения после процесса пайки печатных узлов, такие как органические кислоты или галогениды, локально снижают точку росы. Существенное влияние на возникновение электрохимической миграции оказывают и коррозионные газы, $\mathrm{H}_{2} \mathrm{~S}$ и $\mathrm{CO}_{2}$, которые также растворяются в пленке влаги (рис. 5) [3]. Помимо влажности и используемых материалов на возникновение электрохимической миграции влияют загрязнения после технологических процессов сборки печатных узлов (гигроскопические остатки флюса, щелочи, пыль и кристаллы солей на поверхности).

3. При определенных значениях электрического напряжения и разности потенциалов металлов.

Для оценки степени подверженности сплава электрохимической миграции можно использовать диаграммы Пурбе (рис. 6). Они наглядно отображают термодинамически устойчивые формы ионов или молекул в растворах при различных значениях водородного показателя рН и электродного потенциала Е. Диаграмма Пурбе строится в координатах Е (ордината) - рH (абсцисса) для конкретных сплавов или металлов, находящихся при заданной температуре $25^{\circ} \mathrm{C}$ в водных растворах. С помощью диаграммы Пурбе можно определить, будет ли в заданных условиях металл подвергаться коррозии. Металл должен иметь активную зону в щелочных или кислотных электролитах - это необходимое условие для разрушения металлов и их соединений (серо-голубые зоны на рис. 6). Для конструкторов и технологов радиоэлектронной аппаратуры диаграмма Пурбе является мощнейшим средством выявления коррозии в разных условиях. Сопоставляя диаграммы Пурбе для двух элементов, можно выявить окислительно-восстановительные реакции между их соединениями и, следовательно, возникновение электрохимической миграции при дальнейшей эксплуатации в агрессивных условиях окружающей среды .

\section{РЕШЕНИЯ ДЛЯ ПРЕДОТВРАЩЕНИЯ ВОЗНИКНОВЕНИЯ ЭЛЕКТРОХИМИЧЕСКОЙ МИГРАЦИИ}

Для предотвращения возникновения электрохимической миграции есть три основных подхода:

- правильное проектирование печатной платы и выбор материалов;

- качественная отмывка печатного узла и нанесение влагозащитных покрытий;

- герметизация в корпус.

Рассмотрим их подробнее.

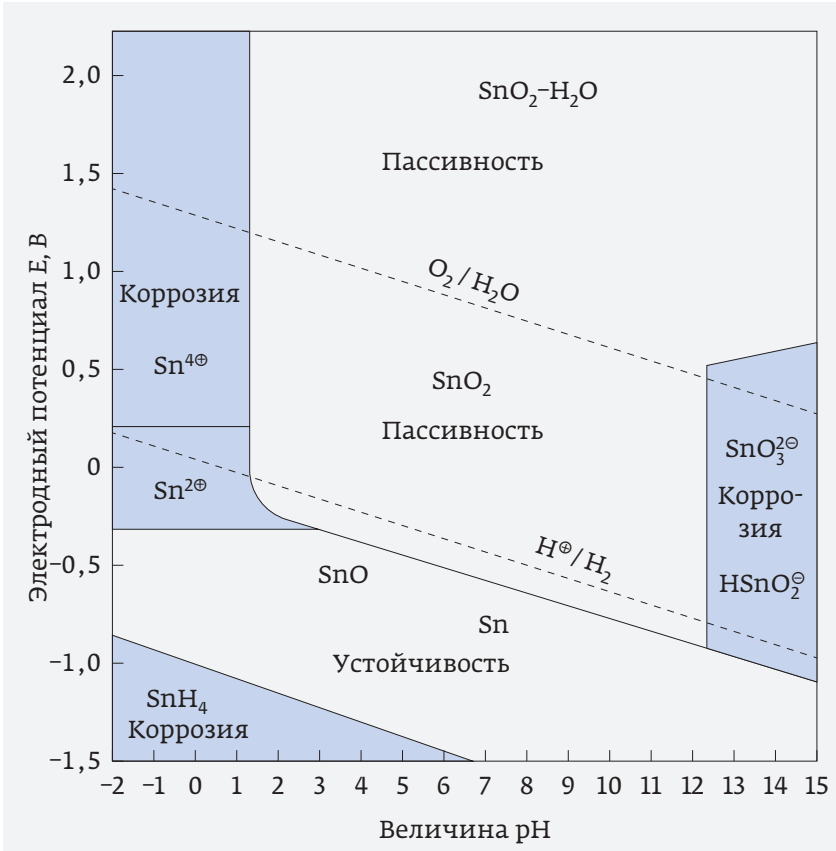

a)

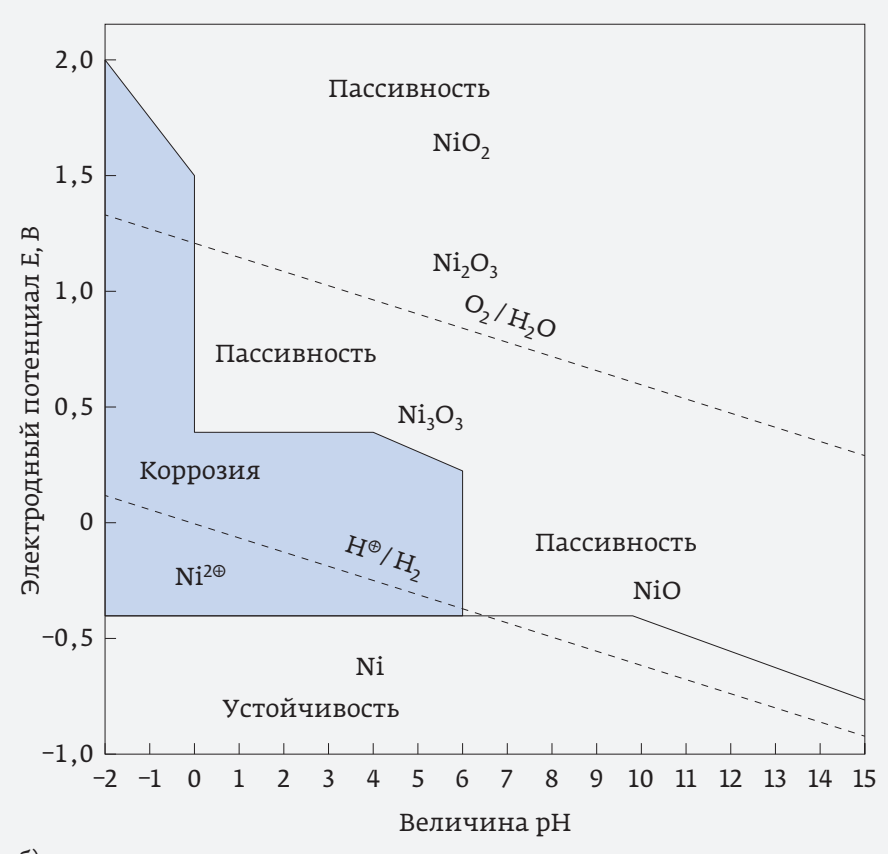

б)

Рис. 6. Диаграмма Пурбе для олова (а) и никеля (б) 


\section{Проектирование печатной платы и выбор материалов}

Материалы, используемые в процессе изготовления и сборки печатной платы, оказывают значительное влияние на возникновение электрохимической миграции. Влияние материалов и конструкции печатной платы может оказаться решающим, однако не многие конструкторы принимают это во внимание на этапе проектирования. В идеале приведенную ниже информацию следует учитывать на этапе разработки, либо уже при создании конечного прототипа изделия.

Для обеспечения оптимальной устойчивости к электрохимической миграции следует правильно выбирать паяльную маску. Гидрофобные жидкие фотоэкспонируемые паяльные маски минимизируют адсорбцию влаги, в отличие от других паяльных масок с различными наполнителями.

При выборе финишного покрытия печатных плат необходимо выбирать то, которое формирует нерастворимые комплексы при эксплуатации в жестких климатических условиях и, в идеале, не формирует гидроксиды в щелочном диапазоне. Примером такого финишного покрытия являются покрытия ENIG (иммерсионное золочение) или ENIPG (финишное покрытие никельпалладий-золото). В условиях конденсации влаги при наличии никеля электрохимическая миграция и дальнейшая коррозия не возникают. Но в любом случае необходимо учитывать поведение металлов и их активную зону в щелочном электролите, а также потенциалы металлов электрохимического ряда (см. рис. 6) [4]

При выборе материалов для пайки рекомендуется избегать гидроксидов серебра как потенциально опасных, так как они легко растворяются в адсорбированной пленке жидкости толщиной всего в несколько молекулярных слоев при относительной влажности 60\% или более. Следует отдавать предпочтение припоям с малым количеством серебра (не более 3\%).

Также возникновение электрохимической миграции можно предотвратить путем грамотного выбора топологии печатной платы (создание электрической изоляции и физическое разделение проводников (анод) и земли (катод)). Но как показывает практика, устойчивость к электрохимической миграции не является главной задачей при проектировании печатных плат, уступая по приоритету требованиям к размерам и электромагнитной совместимости.

\section{Качественная отмывка печатного узла и нанесение влагозащитных покрытий}

Для гарантированного предотвращения электрохимической миграции необходимо выбирать соответствующий процесс отмывки печатного узла. На его поверхности не должно оставаться каких-либо загрязнений,
Таблица 2. Анализ чистоты печатного узла перед нанесением влагозащитного покрытия

\begin{tabular}{|c|c|}
\hline Тест & Контрольное значение \\
\hline $\begin{array}{l}\text { Концентрация ионных } \\
\text { примесей }\end{array}$ & $<0,4 \mathrm{MK} \Gamma / \mathrm{CM}^{2}$ \\
\hline Поверхностное натяжение & $>40 \mathrm{MH} / \mathrm{M}$ \\
\hline Tect ZESTRON ${ }^{\circledR}$ Flux & $\begin{array}{l}\text { Не обнаруживаются } \\
\text { остатки активаторов }\end{array}$ \\
\hline Tест ZESTRON ${ }^{\circledR}$ Resin & $\begin{array}{l}\text { Не обнаруживаются } \\
\text { остатки канифоли }\end{array}$ \\
\hline
\end{tabular}

появившихся после технологических процессов сборки. Для реализации качественной отмывки и длительного срока службы конечного изделия важно обращать внимание на такие основные составляющие, как:

- отмывочная жидкость;

- оборудование для отмывки;

- контроль технологического процесса отмывки

Также, помимо использования современных установок для отмывки и отмывочных жидкостей, все большую популярность набирает плазменная обработка поверхностей перед нанесением влагозащитных покрытий. Плазма увеличивает поверхностную энергию печатного узла после отмывки и улучшает адгезию влагозащитных материалов. Но в любом случае отмывка является обязательной

Как же определить, действительно ли поверхность печатного узла после отмывки чистая? Существуют различные методы анализа качества отмывки, которые дополняют друг друга (табл. 2). При контроле качества отмывки рекомендуется использовать их все, чтобы быть уверенными, что поверхность перед нанесением влагозащитного покрытия является чистой, и при дальнейшей эксплуатации изделия удастся избежать возникновения электрохимической миграции.

Еще один способ предотвращения возникновения электрохимической миграции - нанесение влагозащитного покрытия. Его качество зависит от типа используемых компонентов для монтажа, дизайна печатной платы и чистоты всего изделия.

Также важную роль играет расстояние между отдельными компонентами, поскольку оно должно соответствовать используемому процессу нанесения и типу влагозащитного покрытия. Помимо этого, необходимо обеспечить возможность нанесения покрытия на все компоненты.

Для организации технологического процесса нанесения влагозащитного покрытия необходимо понимать принцип сшивки полимера и его дальнейшие свойства. 


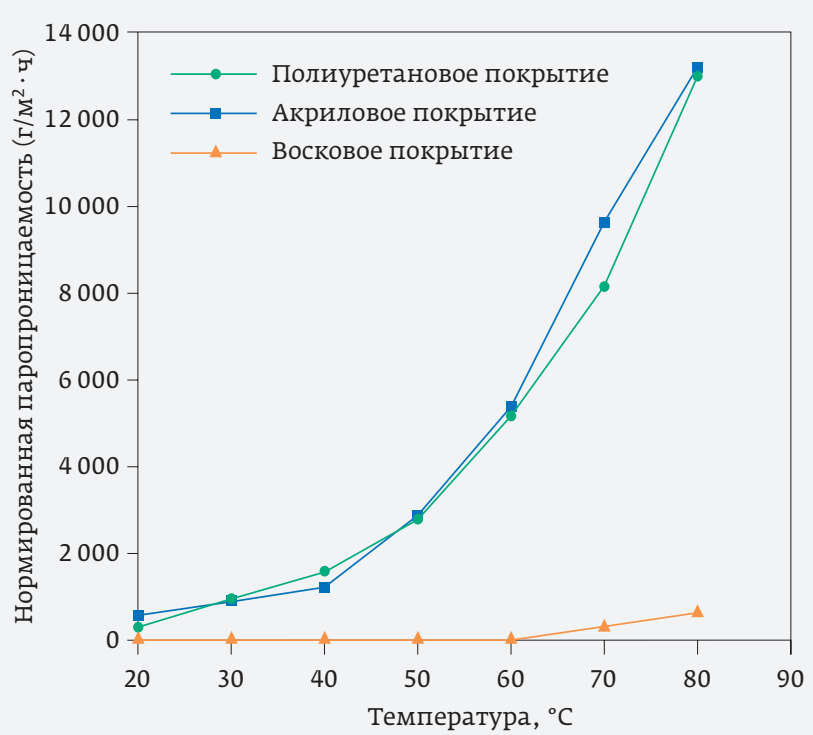

Рис. 7. Паропроницаемость влагозащитных покрытий

Существует мнение, что влагозащитные покрытия препятствуют проникновению влаги на печатный узел. Для восковых покрытий это действительно так, но данные типы покрытий не нашли применения. Самые распространенные влагозащитные покрытия, использующиеся во всем мире, - акриловые, полиуретановые и силиконовые, - являются паропроницаемыми (рис. 7). Именно поэтому необходимо, чтобы перед нанесением покрытия печатный узел был абсолютно чистым. При соблюдении этого условия влагозащитное покрытие выполнит свою функцию защиты даже при условии проникновения в него водяного пара. Вода сможет проникнуть через покрытие, но не сможет сконденсироваться на поверхности печатного узла, влага останется внутри покрытия, не причиняя вреда.

Если влагозащитное покрытие наносится на поверхность без предварительной отмывки изделия, то активаторы и канифоль, оставшиеся на поверхности платы после пайки, станут центрами конденсации и накопления влаги, способствуя формированию электролитов. После проникновения влаги через влагозащитное покрытие это приведет к развитию электрохимической миграции. Поэтому необходимо, чтобы печатный узел был полностью чистым перед процессом нанесения защитных покрытий.

Один из методов анализа качества нанесения влагозащитного покрытия - CORE-тест [5]. Он гарантирует обнаружение дефектов влагозащитного покрытия, проблем с адгезией вследствие некачественной отмывки, токов утечки, вызванных коррозией

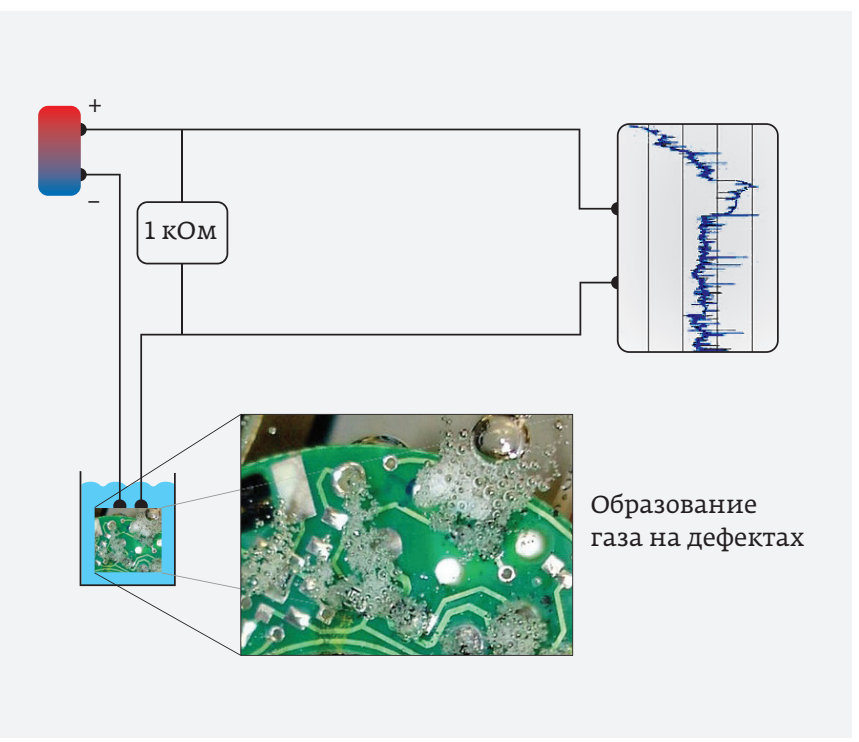

Рис. 8. Схема проведения CORE-теста

и электрохимической миграцией. Тест выполняется в течение 15-30 мин для одного узла. Печатный узел с нанесенным покрытием полностью погружается в деионизованную воду, подключается к источнику питания и работает в режиме ожидания. В ходе испытаний измеряется регистрируемый рабочий ток (рис. 8). Также с помощью данного теста можно определить минимальную необходимую для защиты толщину покрытия. Для этого печатный узел подвергают испытаниям, постепенно уменьшая толщину покрытия, пока не возникнет отказ.

\section{Герметизация в корпус}

В некоторых случаях конструкция устройства, используемые компоненты, проектные ограничения не позволяют применять влагозащитные покрытия. И альтернативой будет герметизация устройства в хорошо вентилируемом корпусе. Он будет выполнять функцию, аналогичную влагозащитным покрытиям - защита устройства от конденсации влаги. Для обеспечения надлежащей вентиляции важна конструкция корпуса. Однако даже при установке изделия в корпус чистота печатного узла играет решающую роль для защиты изделия от возникновения электрохимической миграции.

\section{ОЦЕНКА МЕР ЗАЩИТЫ ОТ ЭЛЕКТРОХИМИЧЕСКОЙ МИГРАЦИИ}

Поскольку каждый из трех подходов для предотвращения электрохимической миграции влечет за собой определенные затраты, следует тщательно проанализировать все защитные меры, чтобы определить, какой подход будет самым эффективным для конкретного применения. Опыт показывает, что наиболее важным критерием является стоимость реализации одной из 
Таблица 3. Критерии приемки по стандарту IPC-9202, глава 9

\section{Раздел Критерий приемки}

9.1 Tect SIR: $>10^{8}$ Oм при температуре $40{ }^{\circ} \mathrm{C}$ и относительной влажности $90 \%$ (тестирование проводится 168 ч, через каждые 24 ч измеряется сопротивление).

ЭХМ: дендриты < 20\% пространства между проводниками

9.2 Ионный анализ: результаты ионной хроматографии должны быть документированы. Предельное значение загрязнений устанавливается производителем/пользователем

вышеприведенных мер предотвращения электрохимической миграции. Чтобы выбрать определенный метод, необходимо испытать изделия после сборки, для чего готовят специальные образцы печатных плат по стандарту IPC-B-52 [6]. Оценка защитных мер проводится на основе критериев приемки, приведенных в главе 9 стандарта IPC-9202 (табл. 3).

В разделе 9.1 стандарта IPC-9202 рассматривается поверхностное сопротивление изоляции. Если в устройстве обеспечено сопротивление изоляции не менее $10^{8}$ Ом, то изменение топологии и остаточный ток утечки соответствуют минимальным требованиям. В разделе 9.2 стандарта рассматриваются остатки ионных загрязнений. Для анализа веществ на поверхности печатного узла используется ионная хроматография. Необходимо проанализировать полученные вещества на их способность порождать коррозию и приводить к появлению электрохимической миграции. В качестве критериев оценки можно использовать предельные значения стандарта IPC-9202 [7]

Эти методы оценки используются для определения пригодности и выбора мер для предотвращения возникновения электрохимической миграции. Если испытываемые прототипы удовлетворяют критериям стандарта IPC-9202, этот подход можно применить уже к реальному изделию. После сборки конечного устройства необходимо также провести его приемку заказчиком, выполнив приемо-сдаточные испытания и тест FMEA (Failure Mode and Effects Analysis - анализ видов и последствий отказов) в дополнение к тестам, определенным в стандарте IPC-9202.

После проведения всех вышеперечисленных испытаний и их положительного результата можно быть уверенными, что такой коварный невидимый враг, как электрохимическая миграция, не потревожит ваши изделия, и они прослужат длительное время. $\because *$

Таким образом, рассмотрены механизм и причины возникновения электрохимической миграции, а также решения для ее предотвращения. К последним относятся оптимальное проектирование печатной платы, качественная отмывка печатного узла, нанесение влагозащитных покрытий и герметизация в корпус. Также описаны методы оценки мер защиты от электрохимической миграции в соответствии с международными стандартами качества.

Не зря электрохимическую миграцию называют невидимым врагом, и часто очень сложно установить, что причиной отказа стала именно она. Поэтому важно правильно организовывать и контролировать технологический процесс сборки, отмывки и влагозащиты изделия для предотвращения дальнейших отказов.

Накопленный опыт и тесное сотрудничество с техническими специалистами компании ZESTRON позволяют ООО "Остек-Интегра" предложить отечественным производителям радиоэлектронной аппаратуры широкие возможности по исследованию и анализу печатных узлов, отмывочных жидкостей и совершенствованию технологических процессов сборки электроники.

\section{ЛИТЕРАТУРА}

1. Schweigart H. Electrochemical migration - partl. How field failures occur and how to avoid them. - ZESTRON. 2016.

2. Leygraf C., Graedel T. Atmospheric Corrosion. - John Wiley and Sons. 2000.

3. Song B., Azarian M. H., Pecht M. G. Effect of Temperature and Relative Humidity on the Impedance Degradation of Dust-Contaminated Electronics // Journal of The Electrochemical Society. 2013. V. 160. Issue 3. PP. C97C105.

4. Hannigan K., Reid M., Collins M. N., Dalton E., Xu C., Wright B., Demirkan K., Opila R. L., Reents W. D., Jr., Franey J.P., Fleming D. A., Punch J. Corrosion of RoHSCompliant Surface Finishes in Corrosive Mixed Flowing Gas Environments // Journal of Electronic Materials. 2012. V. 41. Issue 3. PP. 611-623.

5. Stratmann $\mathbf{M}$. The investigation of the corrosion properties of metals, covered with adsorbed electrolyte layers - A new experimental technique // Corrosion Science. 1987. V. 27. Issue 8. PP. 869-872.

6. Stratmann M., Streckel H. On the atmospheric corrosion of metals which are covered with thin electrolyte layers I. Verification of the experimental technique // Corrosion Science. 1990. V. 30. Issue 6-7. PP. 681-696.

7. IPC-9202 Material and Process Characterization / Qualification Test Protocol for Assessing Electrochemical Performance. 


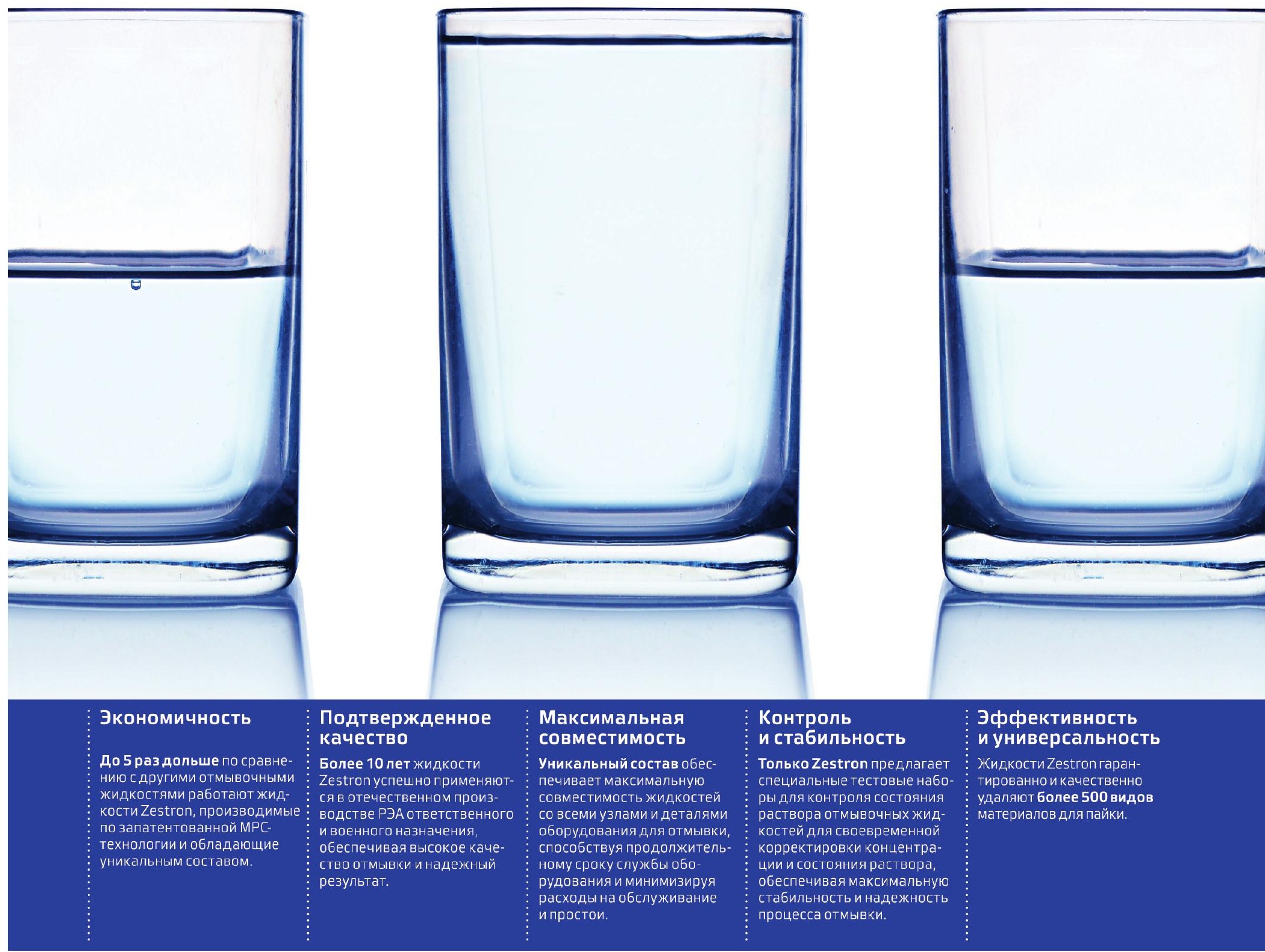

\section{ZIESTRTII \\ High Precision Cleaning}

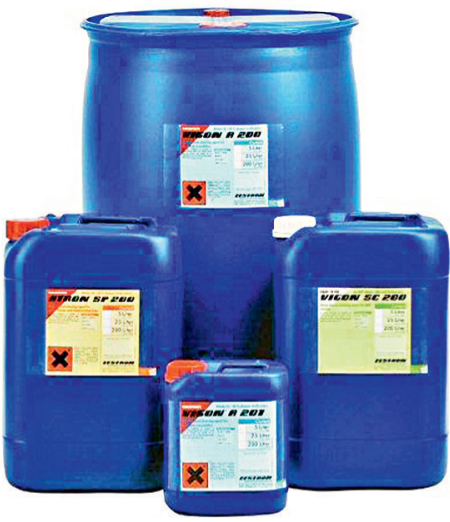

\section{Никаких полумер. Вся полнота преимуществ}

Оригинальные отмывочные жидкости Zestron гарантируют непревзойденное качество отмывки и стабильность результата. Широкий ассортиментный ряд позволяет подобрать отмывочную жидкость для конкретной задачи: в соответствии с типом оборудования и процесса, характером загрязнений, индивидуапьными требованиями.

Отличительной особенностью отмывочных жидкостей Zestron является высокая эффективность: качественная отмывка, совместимость с оборудованием и компонентами, экономичность. Жидкости Zestron успешно зарекомендовали себя на ведущих отечественных производствах РЭА.

Официальный эксклюзивный дистрибьютор Zestron Группа компаний Остек обеспечивает высококвалифицированную техническую и технологическую поддержку, поставку со склада и оперативную доставку по всей России с соблюдением всех условий транспортировки и хранения.

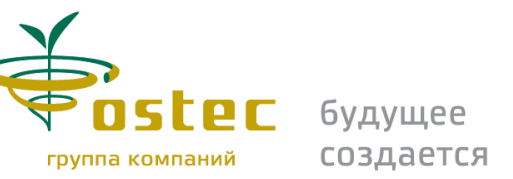

www.ostec-materials.ru (495) 7884444 materials@ostec-group.ru 